\title{
Inhibitory effects of scoparone through regulation of PI3K/Akt and MAPK on collagen-induced human platelets
}

\author{
Dong-Ha Lee ${ }^{1,2}$ (DD \\ Received: 4 March 2020 / Accepted: 23 March 2020 / Published Online: 30 June 2020 \\ (C) The Korean Society for Applied Biological Chemistry 2020
}

\begin{abstract}
When blood vessels are damaged, a fast hemostatic response should occur to minimize blood loss and maintain normal circulation. Platelet activation and aggregation are essential in this process. However, excessive platelet aggregation or abnormal platelet aggregation may be the cause of cardiovascular diseases such as thrombosis, stroke, and atherosclerosis. Therefore, finding a substance capable of regulating platelet activation and suppressing agglutination reaction is important for the prevention and treatment of cardiovascular diseases. 6,7-Dimethoxy-2Hchromen-2-one (Scoparone), found primarily in the roots of Artemisia or Scopolia plants, has been reported to have a pharmacological effect on immunosuppression and vasodilation, but studies of platelet aggregation and its mechanisms are still insufficient. This study confirmed the effect of scoparone on collagen-induced human platelet aggregation, $\mathrm{TXA}_{2}$ production, and major regulation of intracellular granule secretion (ATP and serotonin release). In addition, the effect of scoparone on the phosphorylation of the phosphoproteins PI3K/Akt and mitogenactivated protein kinases (MAPK) involved in signal transduction in platelet aggregation was studied. As a result, scoparone significantly inhibited the phosphorylation of PI3K/Akt and MAPK, which significantly inhibited platelet aggregation through $\mathrm{TXA}_{2}$ production and intracellular granule secretion (ATP and serotonin release). Therefore, we suggest that scoparone is an antiplatelet substance
\end{abstract}

Dong-Ha Lee $(\bowtie)$

E-mail:dhlee@nsu.ac.kr

${ }^{1}$ Department of Biomedical Laboratory Science, Namseoul University, Cheonan 31020, Republic of Korea

${ }^{2}$ Molecular Diagnostics Research Institute, Namseoul University, Cheonan 31020, Republic of Korea

This is an Open Access article distributed under the terms of the Creative Commons Attribution Non-Commercial License (http://creativecommons. org/licenses/by-nc/3.0/) which permits unrestricted non-commercial use, distribution, and reproduction in any medium, provided the original work is properly cited. that regulates the phosphorylation of phosphoproteins such as $\mathrm{PI} 3 \mathrm{~K} / \mathrm{Akt}$ and MAPK and is of value as a preventive and therapeutic agent for platelet-derived cardiovascular disease.

Keywords 6,7-Dimethoxy-2H-chromen-2-one $\cdot$ Granule secretion Mitogen-activated protein kinases $\cdot \mathrm{PI} 3 \mathrm{~K} / \mathrm{Akt} \cdot \mathrm{TXA}_{2}$

\section{Introduction}

Blood plays an absolute role in survival by providing oxygen and nutrients to each organ and tissue while also aiding in the removal of waste products. In order to do this normally, smooth circulation of blood must be achieved. Therefore, when blood vessels are damaged, a rapid hemostatic response should occur in order to minimize blood loss and maintain normal circulation. The response begins with the activation and aggregation of platelets. However, excessive or abnormal platelet aggregation may be a cause of cardiovascular diseases such as thrombosis, stroke, and atherosclerosis. Therefore, the search for a substance capable of regulating platelet activation and suppressing aggregation is important for the prevention and treatment of cardiovascular diseases $[1,2]$. When blood vessels are damaged, platelets are recruited to the site of injury and are activated by vascular activators (collagen, ADP, thrombin). At this time, activated phospholipase $\mathrm{C}$ in platelet membrane hydrolyzes phosphatidylinositol 4,5bisphosphate into inositol 1,4,5-triphosphate $\left(\mathrm{IP}_{3}\right)$ and diacylglycerol, and the resulting $\mathrm{IP}_{3}$ increases $\mathrm{Ca}^{2+}$ concentration in the cytoplasm by opening the $\mathrm{Ca}^{2+}$ channel of the dense tubular system in platelets [3]. During the activation of platelets, arachidonic acid hydrolyzed by cytosolic phospholipase $\mathrm{A}_{2}\left(\mathrm{cPLA}_{2}\right)$ is converted to $\mathrm{TXA}_{2}$, due to the enzymatic action of both $\mathrm{TXA}_{2}$ synthase and cyclooxygenase- 1 , and secreted out of platelets $[4,5]$. The released $\mathrm{TXA}_{2}$ is known to function as a potent agonist that promotes platelet aggregation by binding to other platelet membrane 
receptors [6]. Furthermore, U46619 (9,11-dideoxy-9a.la-methanoepoxy prostaglandin F2a), an analog of $\mathrm{TXA}_{2}$, is known to induce platelet aggregation by phosphorylating myosin light chains and pleckstrin by increasing $\mathrm{Ca}^{2+}$ levels in the cytoplasm [7,8].

Mitogen-activated protein kinases (MAPK) are phosphorylase enzymes known to act on intracellular signaling, which are classified into c-Jun N-terminal kinase (JNK), extracellular signalregulated kinase (ERK), and p38 MAPK, and their roles have been steadily studied [9]. JNK, ERK, and p38 MAPK have been reported to be detected in human platelets and have activity by phosphorylation by several agonists [10-12]. Phosphorylation of this signal transduction molecule is well known to play an important role in inducing platelet granule secretion [13,14]. In addition, MAPK phosphorylates $\mathrm{CPLA}_{2}$ located in the cell membrane, thereby making it active, which is known to generate arachidonic acid from the phospholipids of the platelet membrane, convert it into $\mathrm{TXA}_{2}$, and act on other platelets to trigger activation and aggregation of platelets $[15,16]$. In addition, the PI3K/Akt pathway has demonstrated a vital role in the regulation of platelet function, including the secretion of dense granules in platelets and platelet aggregation [17].

6,7-Dimethoxy-2H-chromen-2-one (Scoparone) found primarily in the roots of Scopolia or Artemisia plants, has been studied to have pharmacological properties such as immunosuppression or vasorelaxation. It has been reported that scoparone inhibits IL-1 $\beta$ mediated inflammatory responses by modulating the PI3K/Akt/ $\mathrm{NF}-\kappa \mathrm{B}$ pathway and thus may be a therapeutic material for joint diseases [18-20]. A previous study has shown that scoparone has the effect of inhibiting thrombus formation through the regulation of cyclic nucleotides in U46619-induced platelets [21]. However, the role of scoparone in platelet aggregation and the mechanism of scoparone on human platelets induced by collagen are currently unknown. In this study, we examined the effectiveness of scoparone on collagen-induced platelet aggregation and its important factors, $\mathrm{TXA}_{2}$ production, platelet granule release, and the phosphorylated proteins of PI3K/Akt and MAPK. Through this, it is expected to contribute to the prevention of cardiovascular diseases caused by platelet aggregation by ingesting eggplants and wormwood, known as plants containing scoparone, as food.

\section{Materials and Methods}

\section{Materials}

Scoparone was received from Avention Corporation (Seoul, Korea) (Fig. 1). Collagen was provided by Chrono-Log Corporation (Havertown, PA, USA). TXB 2 enzyme immunoassay (EIA) kit, ATP assay kit, and serotonin EIA kit are available from Cayman Chemical Co. (Ann Arbor, MI, USA). Other reagents were purchased from Sigma Chemical Corporation (St. Louis, MO, USA). Antibodies and lysis buffers used for western blotting were acquired from Cell Signaling (Beverly, MA, USA). Enhanced

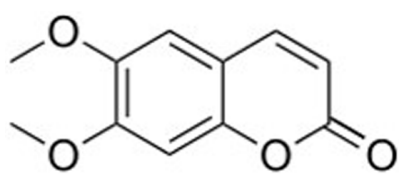

Fig. 1 The structure of scoparone. PIN: 6,7-Dimethoxy-2H-chromen-2one, Chemical formula: $\mathrm{C}_{11} \mathrm{H}_{10} \mathrm{O}_{4}$, Molar mass: $206.19 \mathrm{~g} / \mathrm{moL}$

chemiluminescence solution (ECL) and polyvinylidene difluoride (PVDF) membrane were purchased from General Electric Healthcare (Buckinghamshire, UK).

\section{Preparation of washed human platelets}

The Korean Red Cross Blood Center (Suwon, Korea) provided the human platelet-rich plasma (PRP). Washed platelets were prepared according to the method performed previously [22]. Platelet was obtained by centrifuging PRP at $1,300 \times \mathrm{g}$ for 10 minutes, which was then washed two times with a wash buffer (138 mM NaCl, $12 \mathrm{mM} \mathrm{NaHCO} 3,0.36 \mathrm{mM} \mathrm{NaH} \mathrm{PO}_{4}, 2.7 \mathrm{mM}$ $\mathrm{KCl}, 5.5 \mathrm{mM}$ glucose and $1 \mathrm{mM} \mathrm{Na} \mathrm{N}_{2} \mathrm{EDTA}, \mathrm{pH}$ 6.9). Platelets were suspended with suspension buffer $(138 \mathrm{mM} \mathrm{NaCl}, 12 \mathrm{mM}$ $\mathrm{NaHCO}_{3}, 0.36 \mathrm{mM} \mathrm{NaH} \mathrm{PO}_{4}, 2.7 \mathrm{mM} \mathrm{KCl}, 0.49 \mathrm{mM} \mathrm{MgCl}$, $5.5 \mathrm{mM}$ glucose, $0.25 \%$ gelatin, $\mathrm{pH} 7.4$ ) resulting in the final concentration of $10^{8}$ cells $/ \mathrm{mL}$. All procedures were performed at $25^{\circ} \mathrm{C}$ to avoid platelet aggregation at low temperatures, and this experiment was performed with the approval of the Institutional Review Board (IRB) of Namseoul University (1041479-HR201803-003).

\section{Measurement of platelet aggregation}

In separate samples, with or without scoparone, the washed platelets $\left(10^{8}\right.$ cells $\left./ \mathrm{mL}\right)$ were preincubated in $2 \mathrm{mM} \mathrm{CaCl}_{2}$ at $37^{\circ} \mathrm{C}$ for a total of $3 \mathrm{~min}$, and collagen $(2.5 \mu \mathrm{g} / \mathrm{mL})$ was then added to stimulate. To perform the platelet aggregation assay, an aggregometer was used for $5 \mathrm{~min}$. The platelet aggregation rate (\%) was determined by an increase in light transmission. The scoparone was dissolved using a solution of $0.1 \%$ dimethyl sulfoxide.

\section{Measurement of cytotoxicity}

Cytotoxicity was determined through the leakage of lactate dehydrogenase (LDH) from the cytosol. Human washed platelets $\left(10^{8}\right.$ cells $\left./ \mathrm{mL}\right)$ were incubated for $2 \mathrm{~h}$ at room temperature with various concentrations of scoparone and then centrifuged at room temperature for $2 \mathrm{~min}$ at $12,000 \mathrm{~g}$. The supernatant was measured by LDH assay kit at an optical density of $490 \mathrm{~nm}$.

\section{Measurement of $\mathbf{T X B}_{2}$}

Incubation of the washed platelets $\left(10^{8}\right.$ cells $\left./ \mathrm{mL}\right)$ was performed at $37{ }^{\circ} \mathrm{C}$ for $3 \mathrm{~min}$ with the addition of various concentrations of scoparone, followed by the addition of $2 \mathrm{mM} \mathrm{CaCl} 2$ and stimulation with collagen $(2.5 \mu \mathrm{g} / \mathrm{mL})$ for $5 \mathrm{~min}$. Being a stable metabolite of $\mathrm{TXA}_{2}$, the production of $\mathrm{TXB}_{2}$ was measured by 

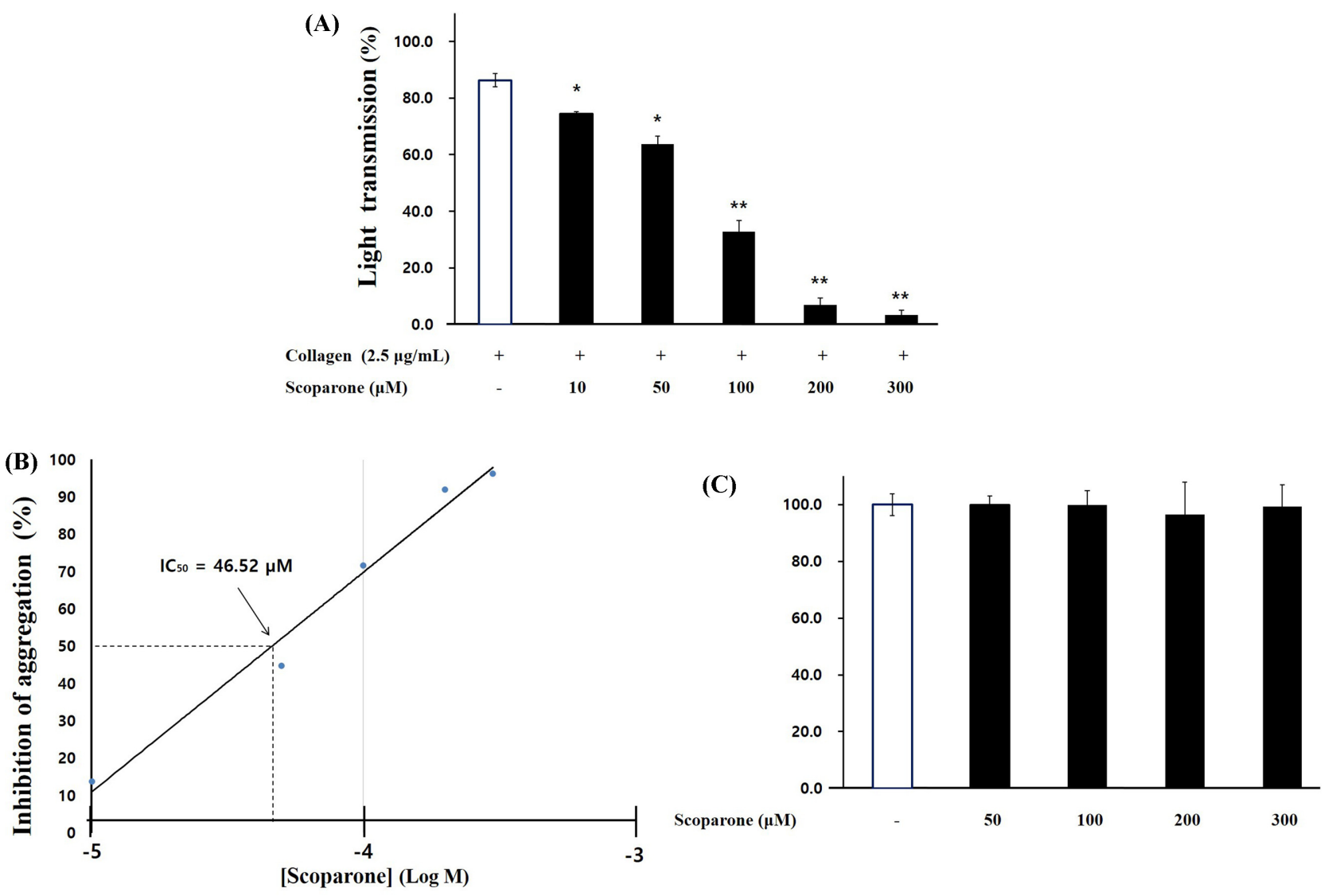

Fig. 2 Effects of scoparone on collagen-induced platelet aggregation. (A) Effects of scoparone pretreatment on collagen-stimulated platelet aggregation. (B) $\mathrm{IC}_{50}$ value of scoparone on collagen-induced platelet aggregation. (C) Cytotoxicity of scoparone on human platelets. Data are expressed as mean $\pm \mathrm{SD}(\mathrm{n}=4) .{ }^{*} p<0.05,{ }^{* *} p<0.001$ compared with the collagen-stimulated platelets

synergy HT multi-reader (BioTek Instruments, Winooski, VT, USA) using the $\mathrm{TXB}_{2}$ EIA kit.

\section{Measurement of ATP release}

The washed platelets $\left(10^{8}\right.$ cells $\left./ \mathrm{mL}\right)$ were incubated at $37{ }^{\circ} \mathrm{C}$ for 3 min with the addition of various concentrations of scoparone, followed by the addition of $2 \mathrm{mM} \mathrm{CaCl}_{2}$ and stimulation with collagen $(2.5 \mu \mathrm{g} / \mathrm{mL})$ for $5 \mathrm{~min}$. After stopping the reaction with ice-cold $2 \mathrm{mM}$ EDTA, the ATP released to the upper layer by centrifugation was measured using an ATP assay kit and a luminometer (BioTek Instruments, Winooski, VT, USA).

\section{Measurement of serotonin release}

The washed platelets $\left(10^{8}\right.$ cells $\left./ \mathrm{mL}\right)$ had been incubated for $3 \mathrm{~min}$ at $37{ }^{\circ} \mathrm{C}$ with the addition of various concentrations of scoparone, followed by the addition of $2 \mathrm{mM} \mathrm{CaCl} 2$ and stimulation with collagen $(2.5 \mu \mathrm{g} / \mathrm{mL})$ for $5 \mathrm{~min}$. After stopping the reaction with ice-cold $2 \mathrm{mM}$ EDTA, the serotonin released to the upper layer by centrifugation was measured by synergy HT multi-reader (BioTek Instruments, Winooski, VT, USA) using a serotonin EIA kit.

\section{Western Immunoblotting}

The addition of a $1 \times$ lysis buffer caused the termination of platelet aggregation. A BCA protein assay kit (Pierce Biotechnology, IL, USA) was used to measure and evaluate the resulting protein concentration of the platelet lysates. After proteins $(20 \mu \mathrm{g}) \mathrm{had}$ been separated through 4-20\% SDS-PAGE, they were relocated onto PVDF membranes. A dilution of 1:1,000 was set for the primary antibodies and the secondary antibodies were set at a dilution of 1:2,000. The use of ECL reagent (General Electric Healthcare, Buckinghamshire, UK) allowed protein band visualization.

\section{Statistical analyses}

The experimental results were expressed using mean \pm standard deviation. Statistical analysis was completed using either ANOVA or unpaired Student's t-test. Scheffe's method was used to compare groups if there were significant differences between group means according to ANOVA. 


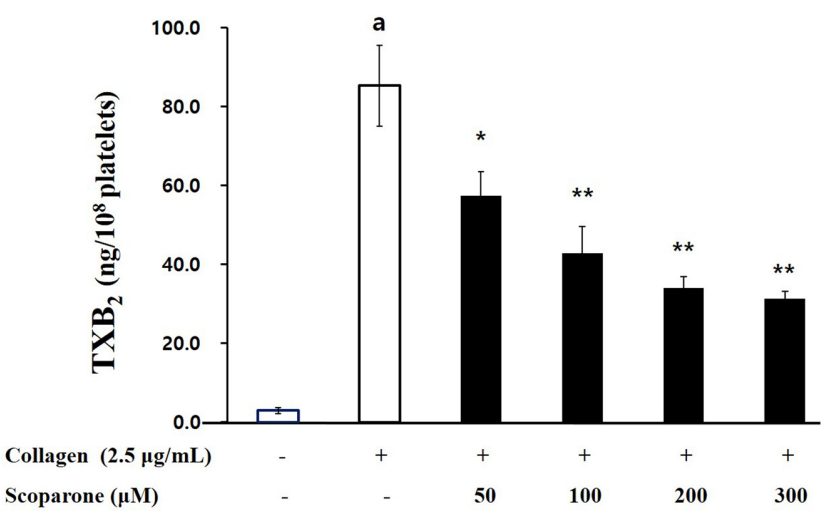

Fig. 3 Effects of scoparone on $\mathrm{TXB}_{2}$ production. Measurement of $\mathrm{TXB}_{2}$ production was described in "Materials and Methods" section. Data are expressed as mean \pm SD $(\mathrm{n}=4)$. ${ }^{\mathrm{a}} p<0.05$ compared with no-stimulated platelets, ${ }^{*} p<0.05,{ }^{*} p<0.001$ compared with the collagen-stimulated platelets

\section{Results}

Effects of scoparone on collagen-induced human platelet aggregation

When platelets were treated with $2.5 \mu \mathrm{g} / \mathrm{mL}$ collagen to induce aggregation, the aggregation rate was $86.3 \pm 2.4 \%$. When scoparone was added at various concentrations (10 to $300 \mu \mathrm{M})$, the increased aggregation by collagen was suppressed dose-dependently without cytotoxicity (Figs. 2B, C). At this time, the half-maximal inhibitory concentration $\left(\mathrm{IC}_{50}\right)$ of scoparone was found to be $46.52 \mu \mathrm{M}$ (Fig. 2B). This shows that scoparone has a potent inhibitory effect on collagen-induced platelet aggregation.

\section{Effects of scoparone on ATP release}

The effect of scoparone on the release of ATP involved in platelet aggregation as an indicator of granule release in platelets was confirmed. As a result, collagen $(2.5 \mu \mathrm{g} / \mathrm{mL})$ increased ATP release from $0.23 \pm 0.01 \mu \mathrm{M}$ in intact cells to $8.39 \pm 0.12 \mu \mathrm{M}$, which was 36.3 times higher than intact cells. However, scoparone (50, 100, 200 and $300 \mu \mathrm{M})$ significantly inhibited the increased ATP release by collagen at $6.53 \pm 0.21,5.01 \pm 0.15,3.03 \pm 0.13$ and $1.34 \pm 0.02$ $\mu \mathrm{M}$, respectively (Fig. 4A).

\section{Effects of scoparone on serotonin release}

The effect of scoparone on the serotonin release involved in hemostasis through vascular contraction as an indicator of granule release in platelets was confirmed. As a result, collagen $(2.5 \mu \mathrm{g} /$ $\mathrm{mL}$ ) increased serotonin release from $7.38 \pm 1.99 \mathrm{ng} / 10^{8}$ cells in intact cells to $173.90 \pm 10.77 \mathrm{ng} / 10^{8}$ cells, which was 23.6 times higher than intact cells. However, scoparone (50, 100, 200 and $300 \mu \mathrm{M})$ significantly inhibited the increased serotonin release by collagen to $128.83 \pm 9.07,80.78 \pm 17.89,48.04 \pm 3.48$ and $27.84 \pm 1.00$ ng $/ 10^{8}$ cells, respectively (Fig. $4 \mathrm{~B}$ ).
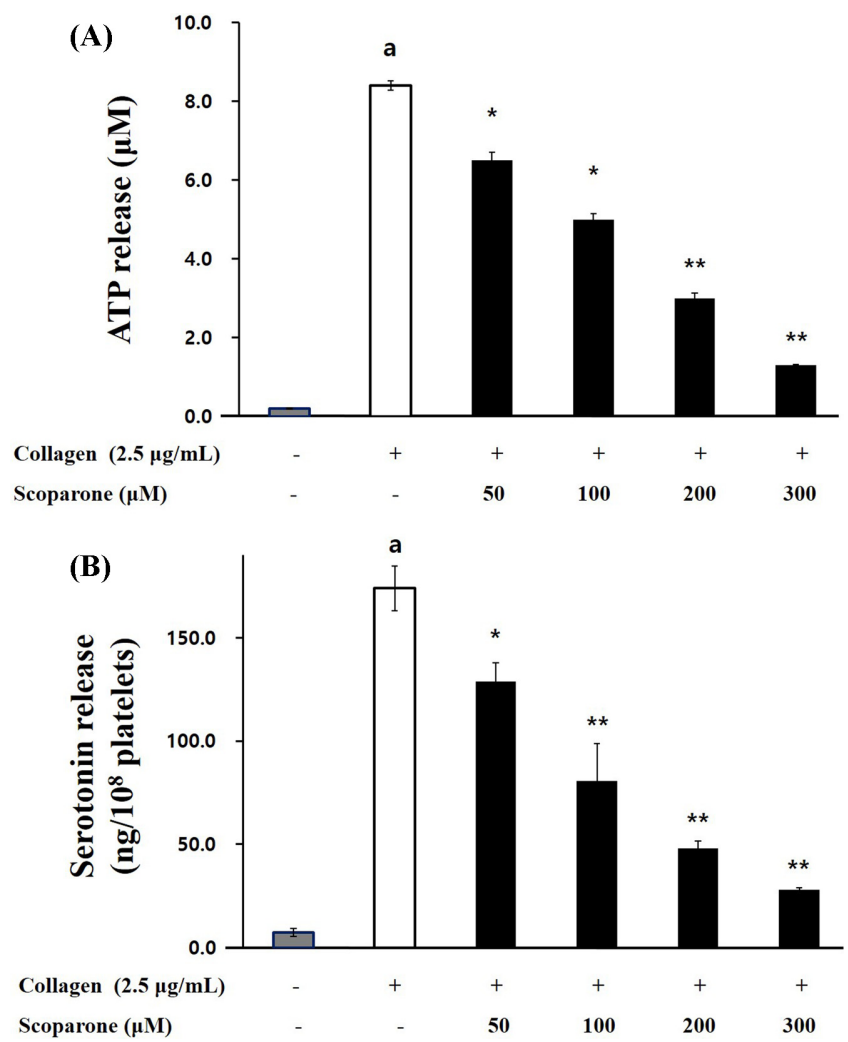

Fig. 4 Effects of scoparone on granule secretion. (A) Effects of scoparone on ATP release. (B) Effects of scoparone on serotonin release. Measurement of ATP and serotonin release was described in "Materials and Methods" section. Data are expressed as mean $\pm \mathrm{SD}(\mathrm{n}=4) .{ }^{\mathrm{a}} p<0.05$ compared with no-stimulated platelets, ${ }^{*} p<0.05,{ }^{* *} p<0.001$ compared with the collagen-stimulated platelets

\section{Effects of scoparone on PI3K and Akt phosphorylation}

The effect of scoparone on the phosphorylation of PI3K and Akt, a phosphoprotein involved in the release of granules from platelets, was confirmed. As shown in Fig. 5, collagen significantly increased the phosphorylation of PI3K compared to intact cells. In addition, the increased phosphorylation of PI3K due to collagen was significantly decreased at concentrations with scoparone greater than $200 \mu \mathrm{M}$ (Fig. 5). Collagen also significantly increased the phosphorylation of Akt, a PI3K target molecule, but significantly decreased at concentrations above $100 \mu \mathrm{M}$ of scoparone (Fig. 5). This shows that scoparone inhibits the phosphorylation of PI3K and Akt promoted by collagen.

\section{Effects of Scoparone on MAPK phosphorylation}

The effect of scoparone on the phosphorylation of phosphoprotein MAPK (ERK, JNK, and p38) involved in platelet granule release and $\mathrm{TXA}_{2}$ production was identified. As shown in Fig. 6, Collagen significantly increased the phosphorylation of JNK and p38 compared to intact cells but did not significantly affect the 


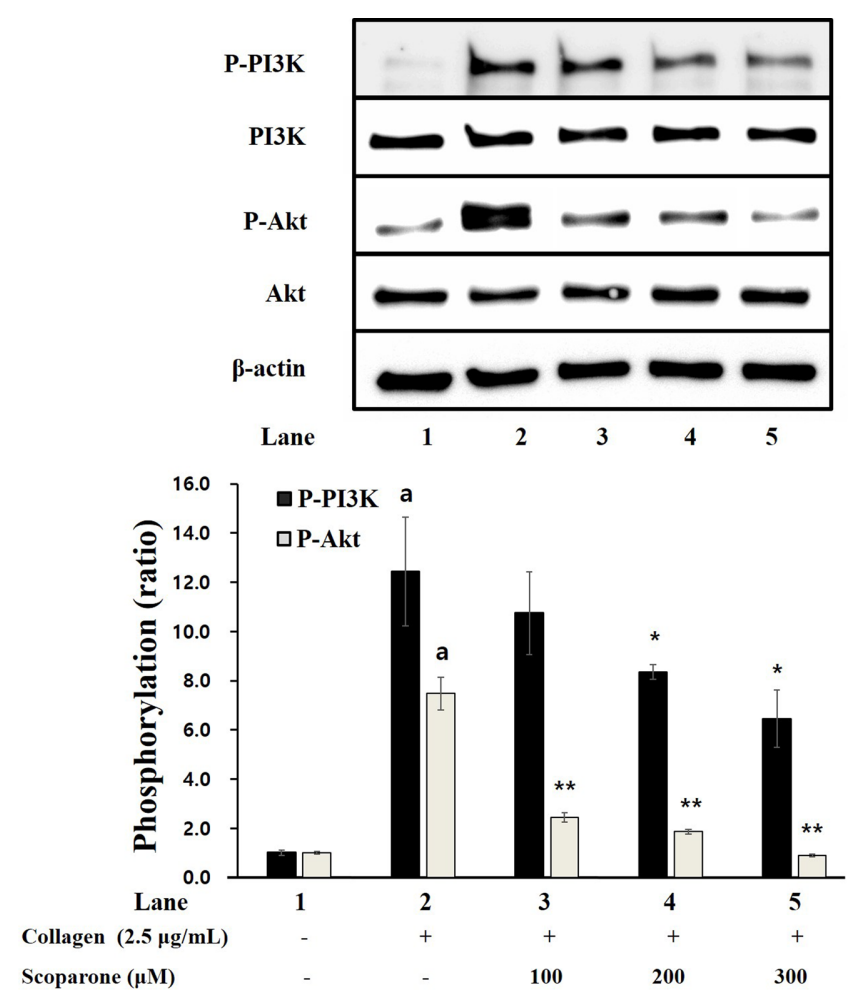

Fig. 5 Effects of scoparone on PI3K and Akt phosphorylation. Western blotting was determined as described in "Materials and Methods" section. Data are expressed as mean $\pm \mathrm{SD}(\mathrm{n}=4) .{ }^{\mathrm{a}} p<0.05$ compared with nostimulated platelets, ${ }^{*} p<0.05,{ }^{* *} p<0.001$ compared with the collagenstimulated platelets

phosphorylation of ERK. In addition, the phosphorylation of JNK or p38 increased by collagen was significantly inhibited at concentrations above 100 or $300 \mu \mathrm{M}$ of scoparone, respectively (Fig. 6). In addition, scoparone significantly inhibited ERK phosphorylation at $200 \mu \mathrm{M}$ (Fig. 6). This shows that scoparone regulates the signaling process of platelet aggregation by inhibiting phosphorylation of ERK, JNK, and p38, known as MAPK.

\section{Discussion}

Although scoparone has been reported to have an effect on platelet activation, the effects of scoparone on platelet aggregation and various signaling substances in the process, in particular phosphoproteins, have not been investigated, therefore the purpose of this study is to clarify the effects of scoparone in collagen-induced platelet aggregation.

PI3K/Akt pathway is well known as a phosphoprotein that functions in platelet signaling transduction, and its phosphorylation has been reported to play a major role in the regulation of platelet function, including the secretion of platelet dense granules and platelet aggregation [17]. In addition, MAPK are well known as phosphorylation enzymes, including ERK, JNK, and p38 MAPK,

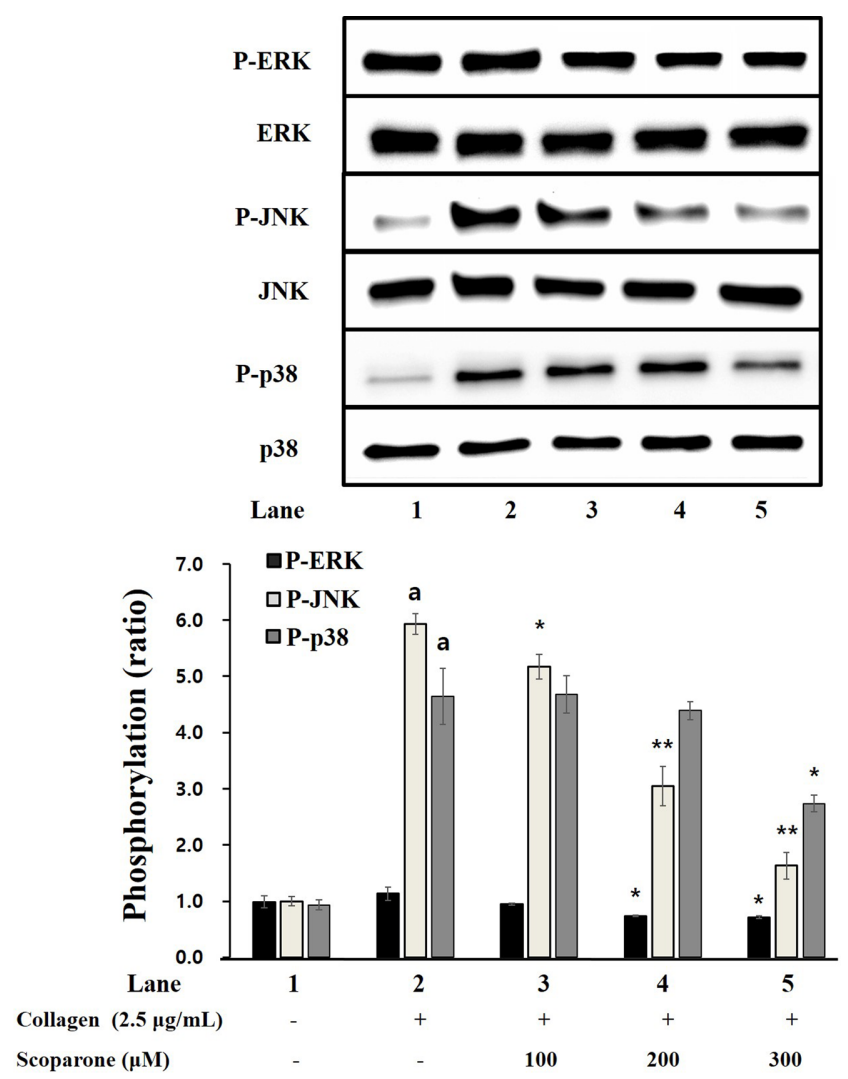

Fig. 6 Effects of scoparone on MAPK phosphorylation. Western blotting was determined as described in "Materials and Methods" section. Data are expressed as mean $\pm \mathrm{SD}(\mathrm{n}=4) .{ }^{\mathrm{a}} p<0.05$ compared with no-stimulated platelets, ${ }^{*} p<0.05, * * p<0.001$ compared with the collagen-stimulated platelets

which are involved in platelet activation and aggregation [9]. MAPK is detected in human platelets and is reported to be activated through phosphorylation when platelets are activated by several agonists [10-12]. According to Mei-Chi et al., phosphorylation of MAPK such as p38 is critical for the release of arachidonic acid, a precursor of $\mathrm{TXA}_{2}$, and the generation of $\mathrm{TXA}_{2}$, leading to platelet aggregation. An important indicator in evaluating components or substances for platelet inhibitory activity is the generation of $\mathrm{TXA}_{2}$ because TXA 2 acts as a powerful autacoid that additionally activates and aggregates other platelets [23]. Therefore, substances that inhibit the production of $\mathrm{TXA}_{2}$ are usefully used as antiplatelet substances, and for example, substances such as aspirin and ozagrel are known [24,25].

In this study, scoparone had a significant concentration-dependent inhibitory effect on collagen-induced platelet aggregation, with a strong $\mathrm{IC}_{50}$ of $14.05 \mu \mathrm{M}$ (Fig. 2). The effects of scoparone on the production of $\mathrm{TXA}_{2}$, an important marker of platelet aggregation, and the secretion of platelet granules (ATP and serotonin release) were measured. In addition, we tried to elucidate the relationship between scoparone and phosphorylation of PI3K/Akt and MAPKs. As the results, it was confirmed that scoparone suppressed 
the production of strongly increased $\mathrm{TXA}_{2}$ by collagen, and ATP and serotonin release, which are indicators of intracellular granule secretion, were strongly reduced by scoparone (Figs. 4B, C). In addition, it was confirmed that the phosphorylation of PI3K/Akt and MAPK, phosphoproteins known to regulate them as signaling molecules, was significantly inhibited by scoparone. In particular, in the case of ERK in MAPK, phosphorylation was not significantly caused by collagen, and the inhibitory effect by scoparone was also weak. There is a result that the degree of inhibiting phosphorylation of ERK in substances inhibited platelet aggregation is weaker than that of JNK or p38 [26]. It has also been reported that the inhibition of ERK pathway has no effect on agonist-induced aggregation of human platelets [27]. In this regard, it seems that further research is needed on how phosphorylation of Erk, JNK and p38 of MAPK is involved in the inhibition of aggregation of human platelets. Anyway, these results suggest that scoparone inhibits the phosphorylation of phosphoproteins such as PI3K/Akt and MAPK, thereby inhibiting platelet aggregation by reducing $\mathrm{TXA}_{2}$ production and intracellular granule secretion (ATP and serotonin release).

In conclusion, we found that scoparone is valuable as an antiplatelet agent to regulate phosphorylation of phosphoproteins in signaling processes such as PI3K/Akt and MAPK. Therefore, scoparone is of great value as an effective therapeutic and prophylactic agent in cardiovascular diseases caused by platelet aggregation.

Acknowledgments Funding for this paper was provided by Namseoul University

Conflict of interest The authors declare no conflict of interest.

\section{References}

1. Jackson SP (2011) Arterial thrombosis $£_{\mid}$insidious, unpredictable and deadly. Nat Med 17: 1423-1436

2. Schwartz SM, Heimark RL, Majesky MW (1990) Developmental mechanisms underlying pathology of arteries. Physiol Rev 70: 1177 1209

3. Payrastre B, Missy K, Trumel C, Bodin S, Plantavid M, Chap H (2000) The integrin alpha IIb/beta 3 in human platelet signal transduction. Biochem Pharmacol 60(8): 1069-1074

4. Morello F, Perino A, Hirsch E (2009) Phosphoinositide 3-kinase signalling in the vascular system. Cardiovasc Res 82(2): 261-271

5. Jennings LK (2009) Role of platelets in atherothrombosis. Am J Cardiol 103: 4A-10A

6. Sabatine MS, Jang IK (2000) The use of glycoprotein IIb/IIIa inhibitors in patients with coronary artery disease. Am J Med 109(3): 224-237

7. Cattanco M, Tenconi PM, Lecchi A, Mannucci PM (1991) In vitro effects of picotamide on human platelet aggregation, the release reaction and thromboxane B2 production. Thromb Res 62: 717-724

8. Su CY, Shiao MS, Wang CT (1999) Differential effects of ganodermic acid $\mathrm{S}$ on the thromboxane A2-signaling pathways in human platelets. Biochem Pharmacol 58: 587-595

9. Adam F, Kauskot A, Rosa JP, Bryckaert M (2008) Mitogenactivated protein kinases in hemostasis and thrombosis. $\mathrm{J}$ Thromb Haemost 6: 2007-2016

10. Bugaud F, Nadal-Wollbold F, Lévy-Toledano S, Rosa JP, Bryckaert M (1990) Regulation of c-jun-NH2 terminal kinase and extracellular-signal regulated kinase in human platelets. Blood 94: 3800-3805

11. Kramer RM, Roberts EF, Strifler BA, Johnstone EM (1995) Thrombin induces activation of p38 MAP kinase in human platelets. J Biol Chem 270: 27395-27398

12. Nadal-Wollbold F, Pawlowski M, Lévy-Toledano S, Berrou E, Rosa JP, Bryckaert M (2002) Platelet ERK2 activation by thrombin is dependent on calcium and conventional protein kinases $\mathrm{C}$ but not Raf-1 or B-Raf. FEBS Lett 531: 475-482

13. Patrono C (1994) Aspirin as an antiplatelet drug. N Engl J Med 330: $1287-1294$

14. Flevaris P, Li Z, Zhang G, Zheng Y, Liu J, Du X (2009) Two distinct roles of mitogen-activated protein kinases in platelets and a novel Rac1MAPK-dependent integrin outside-in retractile signaling pathway. Blood 113: 893-901

15. Kramer RM, Roberts EF, Um SL, Börsch-Haubold AG, Watson SP, Fisher MJ, Jakubowski JA (1996) p38 mitogenactivated protein kinase phosphorylates cytosolic phospholipase A2 (cPLA2) in thrombinstimulated platelets. Evidence that proline-directed phosphorylation is not required for mobilization of arachidonic acid by cPLA2. J Biol Chem 271: 27723-27729

16. McNicol A, Shibou TS (1998) Translocation and phosphorylation of cytosolic phospholipase A2 in activated platelets. Thromb Res 92: 19-26

17. Chuang WY, Kung PH, Kuo CY, Wu CC (2013) Sulforaphane prevents human platelet aggregation through inhibiting the phosphatidylinositol 3kinase/Akt pathway, Thromb. Haemost 109(6): 1120-1130

18. Huang HC, Chu SH, Chao PD (1991) Vasorelaxants from Chinese herbs, emodin and scoparone, possess immunosuppressive properties. Eur J Pharmacol 198: 211-213

19. Huang HC, Lee CR, Weng YI, Lee MC, Lee YT (1992) Vasodilator effect of scoparone (6,7-dimethoxycoumarin) from a Chinese herb. Eur J Pharmacol 218: 123-128

20. Lu C, Li Y, Hu S, Cai Y, Yang Z, Peng K (2018) Scoparone prevents IL$1 \beta$-induced inflammatory response in human osteoarthritis chondrocytes through the PI3K/Akt/NF- $\mathrm{BB}$ pathway. Biomed Pharmacother 106: 1169-1174

21. Lee DH (2019) Antiplatelet effects of scoparone through up-regulation of cAMP and cGMP on U46619-induced human platelets. J Appl Biol Chem 62: 425-431

22. Shin JH, Kwon HW, Lee DH (2019) Ginsenoside F4 inhibits platelet aggregation and thrombus formation by dephosphorylation of IP3RI and VASP. J Appl Biol Chem 62: 93-100

23. Chang MC, Wang TM, Yeung SY, Jeng PY, Liao CH, Lin CC, Lin BR, Jeng JH (2011) Antiplatelet effect by p-cresol, a uremic and environmental toxicant, is related to inhibition of reactive oxygen species, ERK $/ \mathrm{p} 38$ signaling and thromboxane A2 production. Atherosclerosis 219(2): 559 565

24. Cipollone F, Patrignani P, Greco A, Panara MR, Padovano R, Cuccurullo F Patrono C, Rebuzzi AG, Liuzzo G, Quaranta G, Maseri A (1997) Differential suppression of thromboxane biosynthesis by indobufen and aspirin in patients with unstable angina. Circulation 96: 1109-1116

25. Patrono C (2001) Aspirin: new cardiovascular uses for an old drug. Am J Med 110: 62S-65S

26. Irfan M, Jeong D, Saba E, Kwon HW, Shin JH, Jeon BR, Kim S, Kim SD, Lee DH, Nah SY, Rhee MH (2019) Gintonin modulates platelet function and inhibits thrombus formation via impaired glycoprotein VI signaling. Platelets 30(5): 589-598

27. McNicol A, Jackson EC (2003) Inhibition of the MEK/ERK pathway has no effect on agonist-induced aggregation of human platelets. Biochem Pharmacol 65(8): 1243-1250 